\title{
Rheumatoid Arthritis: Are Current Research-based Guidelines Clinically Relevant?
}

In this issue of The Journal, Ciubotariu, et al ${ }^{1}$ examine joint damage and progression in patients with rheumatoid arthritis during clinical remission. They report less erosion progression in patients receiving biologic disease-modifying antirheumatic drugs (DMARD) compared to nonbiologic DMARD (nbDMARD). In addition, scores on the Health Assessment Questionnaire-Disability Index (HAQ-DI), a secondary outcome of disability, were better for patients taking biologics than for those taking nbDMARD. Despite the statistically significant differences noted, the changes were very small and one might wish to consider whether statistical differences translate into clinically relevant ones.

First, there are issues with the meaning of small changes in radiological progress. Second, there are more basic issues regarding the pathogenetic meaning when radiographs do not change.

The minimal clinically important difference in radiographic progression is variable depending on the methods used, ranging from 2.3-5.5 units using the Larsen vs the Sharp/van der Heijde methods ${ }^{2}$. With changes of only 0.9 (adjusted data) in the biologic DMARD and 1.37 in the nbDMARD groups over 3 years in radiographic progression, it is clear that the differences are far below this number. Even if one assumes a linear change per year (not at all guaranteed), this means that using a difference in the rate of erosion of 0.4 units per year, one would need a minimum of 6-13 years of therapy to reach even a minimal clinically significant difference between treatments, radiographically. If not radiographically different, does this study posit a clinically significant functional difference between therapies? Given that the minimal clinically significant change in HAQ-DI is at least 0.22 (and is often considered to be 0.4 ), combined therapy would still have to continue for 3-5 years (given that the HAQ-DI difference noted was -0.1 vs -0.18 in the 2 groups - a difference of 0.08 ) to separate the 2 regimens in a functionally meaningful way. Thus, this article seems to be pointing to a very small and probably not clinically meaningful difference between therapies. It is true, of course, that the literature supports Ciubotariu, et al's conclusion, so their article could be considered supportive of that contention, even if weakly so.

The pathogenetic meaning of radiographic change should also be considered. Historically, the cessation of radiographic progression has been used as 1 definition of disease remission, because that cessation is thought to reflect little or no inflammation. The lack of radiographic progression, then, could be a surrogate for lack of clinical progression or preservation of function over the longer term. However, a number of studies concluded that radiologic progression continues despite attaining clinical remission, regardless of the criteria used to define this remission ${ }^{3,4}$. Additionally, the timepoint at which radiographic progression is examined appears to be significant. Aletaha, et al reported that the level and duration of particular disease activity (in this case, remission) are important determinants for radiographic progression ${ }^{5}$. Therefore, the point at which a radiograph is obtained is key to determining remission. This raises questions about whether radiological progression using observational data over such a limited period (as the observational trial under consideration) is really useful, either in clinical trials or in clinical practice.

Ultrasound, magnetic resonance imaging (MRI) techniques, and positron emission tomography scans, as well as the introduction of single photon emission-computed tomography scans, may allow greater in-depth evaluation of the joint space, including the inflammatory or preclinical component of bone damage ${ }^{6}$. These techniques are not yet fully validated nor are their predictive values yet defined, relative to standard radiographic films ${ }^{7}$. However, given that such validation will occur, with increased ability to detect subclinical disease and inflammation, we again raise the question as to the utility of radiologic remission.

Are there, then, other ways to reconcile the lack of radiographic progression with a clinical measure of remission, thus restoring the value of plain radiographs to clinical trials? A score of $<2.6$ on the 28 -joint Disease Activity Scale (DAS28) ${ }^{8}$ has been widely used as a measure of remission and it could be compared to radiographic progression. However, many if not most investigators admit that DAS28 $<2.6$ often represents low disease activity rather than true clinical remission. Clinical Disease Activity Index $(\mathrm{CDAI})<2.8$ and simplified Disease Activity Index $(\mathrm{SDAI})<3.3$ and the "Boolean American College of Rheumatology/European League Against Rheumatism" criteria of remission are all far more stringent criteria of

\section{See Joint damage progression in RA remission, page 1576}


remission and should be correlated with radiographic change (or lack thereof). Some investigators argue that given their stringent formulae, these criteria (especially the Boolean) occur so infrequently that they offer limited application outside clinical trials settings ${ }^{9}$. In a recent study by Svensson, et $a l^{10}$, DAS28 identified more patients in sustained remission than did either SDAI or the Boolean criteria. Hence, it was proposed as the preferred tool in longterm observational studies, although the lack of correlation with longterm outcomes considerably weakens such an argument.

The issue of the meaning of remission, then, remains open. Logic would dictate that those definitions (CDAI, SDAI, Boolean) that completely abrogate inflammation are more likely to reflect true remission and would correlate with better longterm outcome, and thus are more appropriate for correlation with imaging such as radiographs. None of these measures were used in Ciubotariu, et al's article ${ }^{1}$, unfortunately, thus not furthering either their argument or the larger argument about the most appropriate measure for remission. Alternatively, one would consider the use of outcomes of disability as a measure of clinical remission. If one were to agree to this, one then would debate whether a self-reported measure such as HAQ-DI should be used. One may argue that HAQ-DI correlates well with disease activity. Saleem, et $a l^{11}$, pointed out that ultrasound power Doppler signaling as well as HAQ-DI were independently associated with risk of a flare when studying patients who were in remission. However, structural limitation is bound to have ceiling effects, in which very high HAQ-DI and/or modified total Sharp score reach an upper plateau. That is exactly what was seen by Tanaka, et $a l^{12}$. Other factors, which would limit the use of HAQ-DI or other functional measures, are comorbid conditions, and could confound correlations $^{13}$. An example could be severe heart failure, where even complete RA remission would not improve function in a person who is nearly bedridden.

Ciubotariu, et $a l^{1}$ raise questions about the meaning of remission, and as noted, do not really answer them. However, their article remains very useful in bringing these issues to the forefront: (1) how much change in a measure is needed to be clinically rather than statistically relevant; (2) which measures of clinical remission are relevant; and (3) what is the meaning of radiographic remission in an era of other more sensitive imaging of inflammation?

Those questions, in turn, raise these points: (1) is seeking remission (by an agreed measure and an agreed amount) relevant? Both Ciubotariu, et al's and our answer is "yes"; (2) is remission attainable? Both Ciubotariu, et al and we would say "yes" although our definitions and requirements are different; and (3) are the definitions realistic? Ciubotariu, et $a l^{1}$ would say yes and we would only say yes if one used other definitions (more stringent), other imaging techniques (e.g., MRI or ultrasound), and another study design (e.g., a longer study or a more responsive population of patients).
SUZANNE KAFAJA, MD,

Clinical Instructor;

DANIEL E. FURST, MD

Carl M. Pearson Professor of Rheumatology,

Director of Therapeutic Research,

Department of Rheumatology,

David Geffen School of Medicine,

University of California at Los Angeles,

1000 Veteran Ave., Room 32-59,

Los Angeles, California 90095-1670, USA.

Address correspondence to Dr. Furst. E-mail: defurst@mednet.ucla.edu

\section{REFERENCES}

1. Ciubotariu E, Finckh A, Gabay C. Joint damage progression in patients with rheumatoid arthritis in clinical remission. Do biologics perform better than conventional antirheumatic drugs? J Rheumatol 2014;41:1576-82.

2. Bruynesteyn K, van der Heijde D, Boers M, Saudan A, Peloso P, Paulus $\mathrm{H}$, et al. Determination of the minimal clinically important difference in rheumatoid arthritis joint damage of the Sharp/van der Heijde and Larsen/Scott scoring methods by clinical experts and comparison with the smallest detectable difference. Arthritis Rheum 2002;46:913-20.

3. Lillegraven S, Prince FH, Shadick NA, Bykerk VP, Lu B, Frits ML, et al. Remission and radiographic outcome in rheumatoid arthritis: application of the 2011 ACR/EULAR remission criteria in an observational cohort. Ann Rheum Dis 2012;71:681-6.

4. Rezaei H, Saevarsdottir S, Forslind K, Albertsson K, Wallin H, Bratt $\mathrm{J}$, et al. In early rheumatoid arthritis, patients with a good initial response to methotrexate have excellent 2-year clinical outcomes, but radiological progression is not fully prevented: data from the methotrexate responders population in the SWEFOT trial. Ann Rheum Dis 2012;71:186-91.

5. Aletaha D, Funovits J, Breedveld FC, Sharp J, Segurado O, Smolen JS. Rheumatoid arthritis joint progression in sustained remission is determined by disease activity levels preceding the period of radiographic assessment. Arthritis Rheum 2009;60:1242-9.

6. Zeman MN, Scott PJ. Current imaging strategies in rheumatoid arthritis. Am J Nucl Med Mol Imaging 2012;2:174-220.

7. Gandjbakhch F, Haavardsholm EA, Conaghan PG, Ejbjerg B, Foltz $\mathrm{V}$, Brown AK, et al. Determining a magnetic resonance imaging inflammatory activity acceptable state without subsequent radiographic progression in rheumatoid arthritis: results from a followup MRI study of 254 patients in clinical remission or low disease activity. J Rheumatol 2014;41:398-406.

8. Fransen J, Creemers MC, Van Riel PL. Remission in rheumatoid arthritis: agreement of the disease activity score (DAS28) with the ARA preliminary remission criteria. Rheumatology 2004;43:1252-5.

9. Felson DT, Smolen JS, Wells G, Zhang B, van Tuyl LH, Funovits J et al. American College of Rheumatology/European League against Rheumatism provisional definition of remission in rheumatoid arthritis for clinical trials. Ann Rheum Dis 2011;70:404-13.

10. Svensson B, Andersson ML, Bala SV, Forslind K, Hafström I; BARFOT study group. Long-term sustained remission in a cohort study of patients with rheumatoid arthritis: choice of remission criteria. BMJ Open 2013;3:e003554.

11. Saleem B, Brown AK, Keen H, Nizam S, Freeston J, Wakefield R, et al. Should imaging be a component of rheumatoid arthritis remission criteria? A comparison between traditional and modified composite remission scores and imaging assessments. Ann Rheum Dis 2011;70:792-8.

12. Tanaka Y, Yamanaka H, Saito K, Iwata S, Miyagawa I, Seto Y, et al. Structural damages disturb functional improvement in patients with rheumatoid arthritis treated with etanercept. Mod Rheumatol 2012;22:186-94

13. Krishnan E, Häkkinen A, Sokka T, Hannonen P. Impact of age and comorbidities on the criteria for remission and response in rheumatoid arthritis. Ann Rheum Dis 2005;64:1350-2.

J Rheumatol 2014;41:1569-70; doi:10.3899/jrheum.140352

Personal non-commercial use only. The Journal of Rheumatology Copyright @ 2014 . All rights reserved. 